\title{
College Financial Management System Research and Design
}

\author{
Xinxin SONG \\ Department of Information Engineering, Jilin Business and Technology College \\ 130062, Changchun, China \\ 308183038@qq.com
}

Keywords: Information; Finance; Management system; University; ASP.net

Abstract. With the rapid development of computers, information management systems have also become popular in various fields. Financial management of colleges and universities is a very complex task, in order to improve the financial management efficiency of universities; the paper information management system of colleges and universities was conducted research and design. Through user management module, account management module, the student fee module, payroll management module and employee information management module five modules to better interpret the content of financial management information system. System precludes the use of B / S mode of related technologies, and described the information and function of each system, so that college and other institutions financial management information system is better applied and services to schools.

\section{Introduction}

Financial institutions of higher education management information system is an important part of the management of universities, colleges and universities have each office has a close relationship with the financial system. In order to improve the level of information technology universities, colleges of education to achieve better management; institutions of higher learning in order to achieve its management efficiency, better sharing of information in the financial management information system, the paper through the work of financial management in universities propose solutions to practical problems of design ideas, the content of financial management information systems and school information system combined together [1].

\section{System Analysis}

Development of financial management information system is primarily intended to eliminate the "islands of information" to provide better service to the school staff, students and decision-making leadership. So, to design information complete, easy to operate, fully functional, financial management information system can safely operate needs to complete the construction of several modules:

Accounting processing module: The management of financial data processing schools, such as: financial data entry, budget assignment, accounts preparation, generation and other financial statements.

Asset management module: Related to logistical and financial affairs of the school management, including the increase in assets, change, obsolescence management, infrastructure-related contract management, teachers' housing, and water and electricity management.

Compensation Management module: Salaries for faculty, staff records management, to complete the wage changes and other work.

Student fee management module: To achieve the existing student tuition payment of school textbooks and other outside USA administration.

Information management module: Permissions clear, grade school teachers and students to realize the query-related information, feedback function [2]. 


\section{System Architecture and Principles}

Major Structural Way. It adopts the common B / S three-tier structure, specifically is shown in Figure 1, this structure is widely used, easy to be accepted, mature technology.
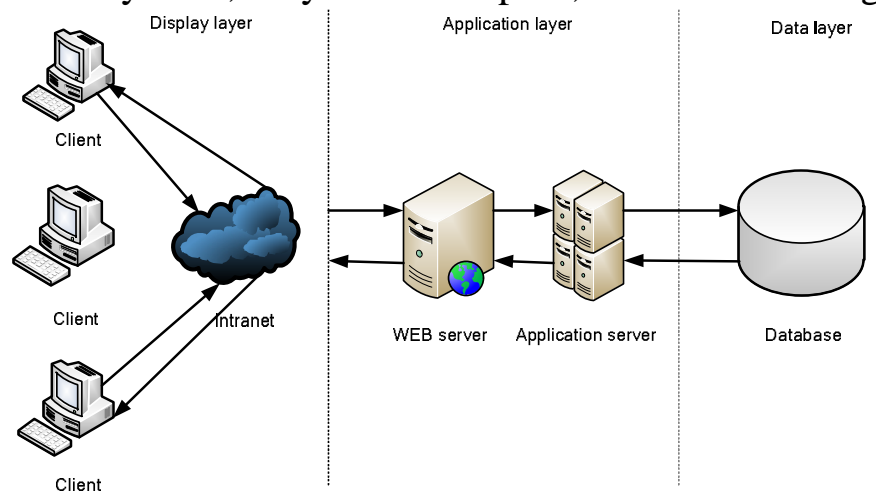

Figure 1. B / S structure diagram

System Plan. All users on the college financial management information system access, school leaders and department heads can develop school or department to understand the use of funds by visiting, assistant decision making; General staff such as teachers, students, etc. can access the system to understand the situation of their own costs; The financial personnel and various departments staff carries on the correlation data through the system operation, maintains and so on [3]. System application pattern is shown in Figure 2.

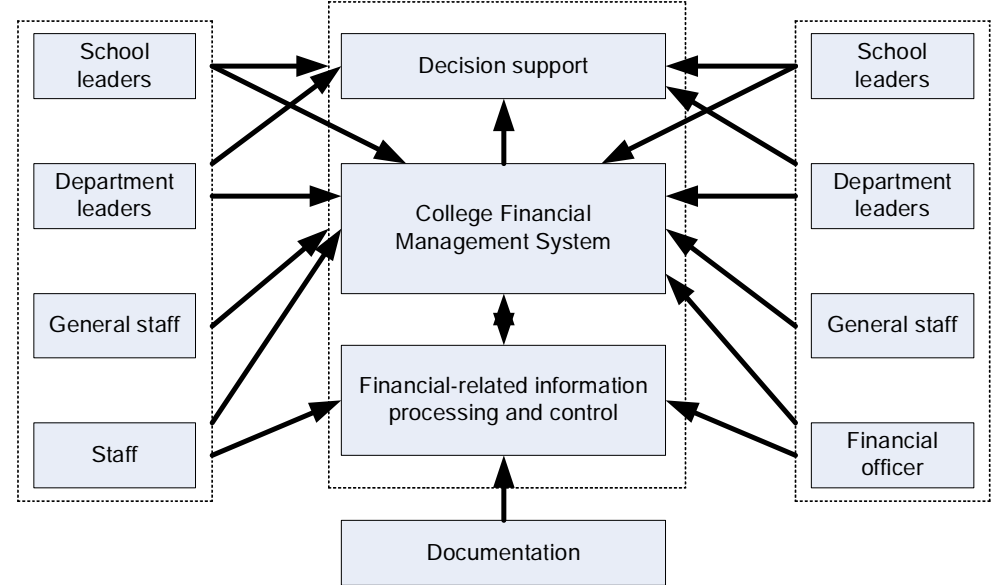

Figure 2. System application modes

Overall System Function Module. The overall function module design is shown in Figure 3.

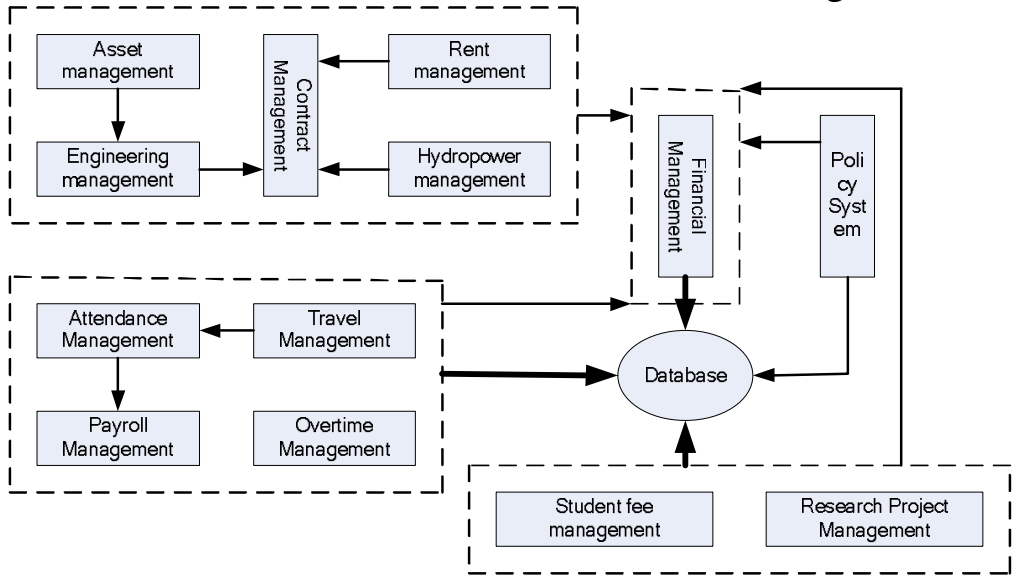

Figure 3.The overall functional block diagram

Financial Management Process. Traditional financial business processes of financial accounting are responsible for collecting the original credentials and real and legitimate their original documents for review [4]. When financial expenses, fill out and generate original documents to prove financial 
revenue and expenditure, a clear financial responsibility. Financial accounting system is shown in Figure 4.

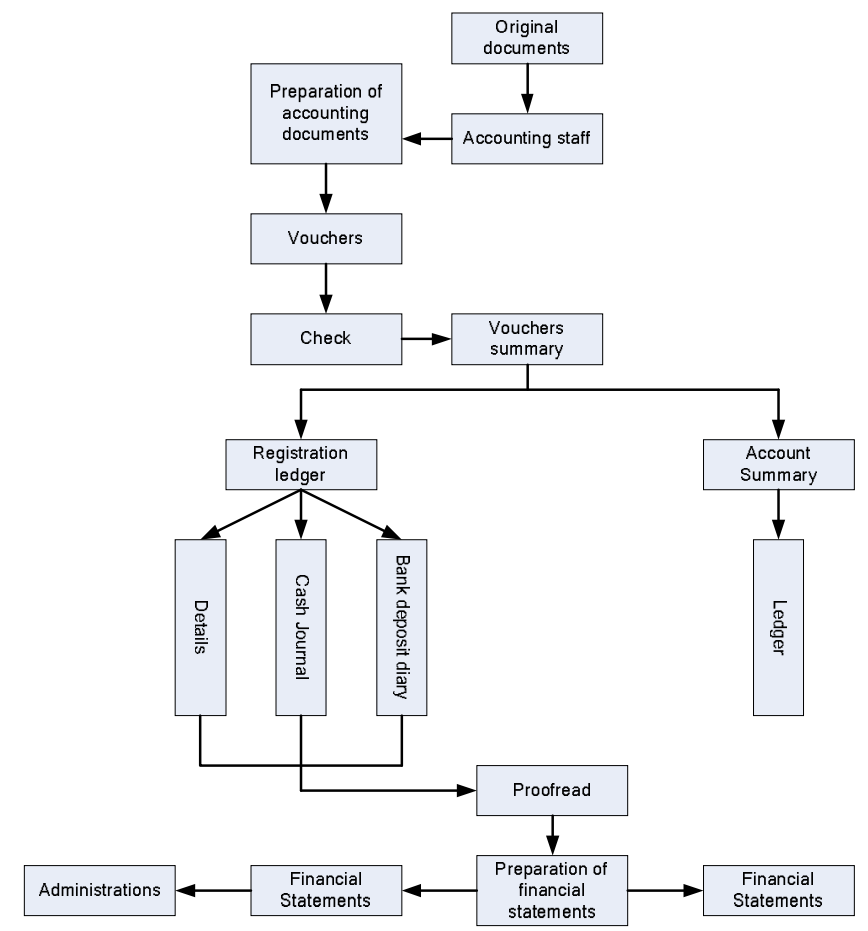

Figure 4.Financial accounting system processes

Finance staff by the original certificate records and generate vouchers. Reimbursement of staff to fill single reimbursement, reimbursement staff pays various taxes and fees, depending on financial officer's reimbursement voucher data entry bookkeeping vouchers. Accountant With the legitimacy and authenticity of the original document, and then develop a review under vouchers finance staff, access to all information and documents to fill in the financial amount of integrity [5]. By the end of the financial officers of the month aggregated is amount of expenditure and fill out vouchers.

\section{System Specific Design}

The Overall System Architecture. Universities Financial Management Information System in accordance with the functional classification can be divided into many modules: user management module, accounts processing function module, payroll management information module, tuition and employee information management function module function module. Financial management information module is shown in Figure 5.

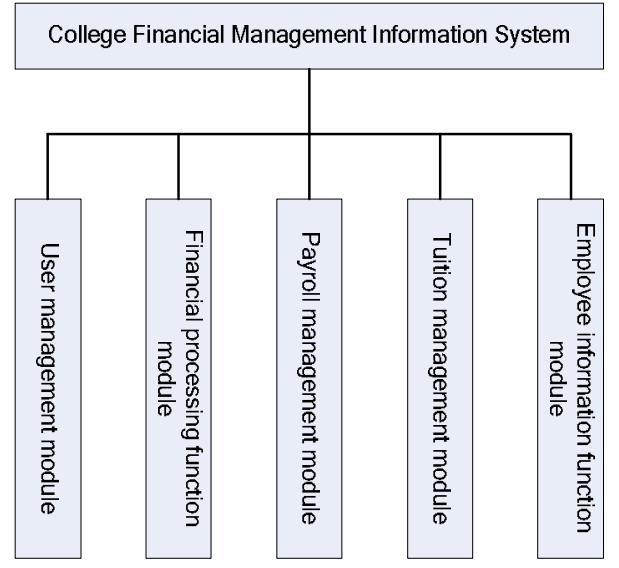

Figure 5.Financial management information modules

Accounts Processing Function Module. Accounting processing module into a voucher management module I, treasury management module, the books management module and report modules as shown in the four modules to analyze design, it is shown in Figure 6. 


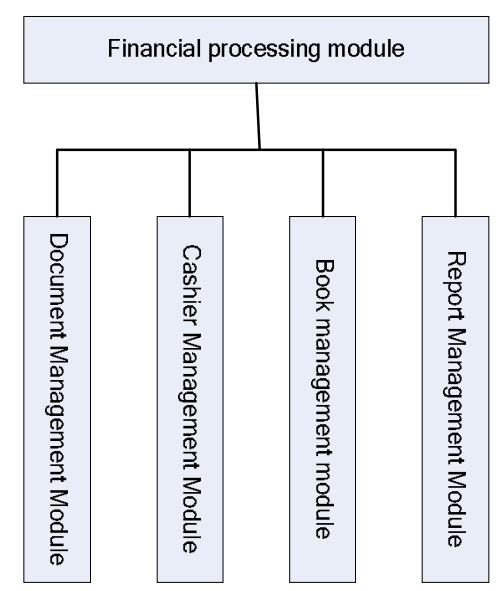

Figure 6.Accounting treatment system module

User Management Module. User management module consists mainly of four parts rights management system; add users, change passwords, and system maintenance functions [6]. Meanwhile, the system administrator has the highest administrative privileges system; user information can query and understand. It is shown in Figure 7.

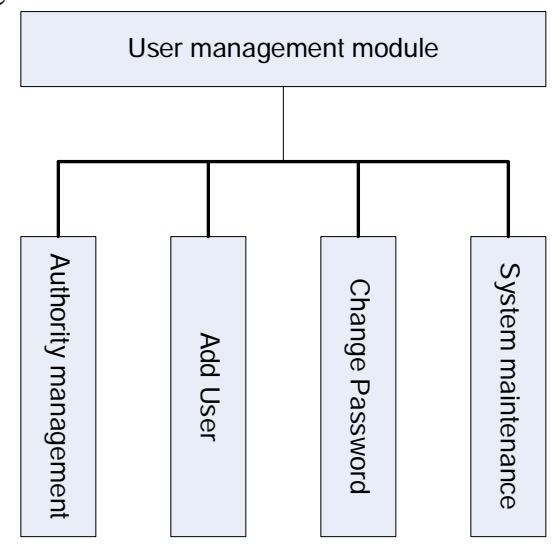

Figure 7.User management module

\section{Conclusions}

In the system design and implementation process, mainly to consider how to combine the existing school network technology, as far as possible to make the user easy to learn. However, due to limited personal technology, the entire system still has many deficiencies, to be further improved and improved next.

\section{References}

[1] X.H. Hu.Financial Management, Shanghai: Shanghai Lixin Accounting Press, 2009

[2] H.Wang.University Network Accounting Information System Research, Beijing University of Technology, 2005

[3] L.Zhang.Financial Management System Mode, Research Management, 2006

[4] J.Lan.Design and Implementation Ranger budgeting system: Tianjin University, 2006.

[5] L.G.Zhu.Design enrollment and employment information management system design and implementation, WEB-based Hebei University of Science and Technology, 2009.

[6] B.Wang. Design and Implementation of B / S mode network online examination system, University of Electronic Science and Technology, 2008. 